\title{
Time-Varying Parameter Population Health Models and the Health Effects of Social Services vs. Health Care Spending: An Application to Canada
}

\author{
Akhter Faroque ${ }^{1}$ \\ ${ }^{1}$ Department of Economics, Laurentian University, Canada \\ Correspondence: Akhter Faroque, Department of Economics, Laurentian University, Ramsey Lake Road, \\ Sudbury, Ontario P3E 2C6, Canada. Tel: 705-675-1151 (ext. 4263). E-mail: afaroque @laurentian.ca
}

Received: June 12, 2020

Accepted: July 6, 2020

Online Published: August 4, 2020

doi:10.5539/ijef.v12n9p23

URL: https://doi.org/10.5539/ijef.v12n9p23

\begin{abstract}
A recent strand of the health literature claims that, for a healthier population, governments in high-income countries such as Canada should shift expenditure from health care to the provision of social services. Authors in this literature make this recommendation based on the finding that in standard static constant-parameter health models, the ratio of social services to health care spending is systematically associated with higher life expectancy and lower mortality across the OECD countries. We evaluate the robustness of this important claim to (i) likely time-variation in the model parameters (ii) delayed effects of health determinants and (iii) to disaggregation of health care spending into its major components.

Methods: We conduct a longitudinal study of the comparative empirical performances of four time-varying parameter, dynamic and disaggregated health-indicator models relative to the benchmark models typically estimated in the literature, using a Canadian national dataset.

Results: We find evidence that spending on social services may indeed increase life expectancy and lower mortality more than spending on health care; but this finding emerges only in dynamic models that allow for time variation in the coefficients. Disaggregation generally shows that hospital care lowers mortality by more than all other categories of spending, including social services.
\end{abstract}

Keywords: health care, social services, time-varying parameters, dynamics

\section{Introduction}

During the past half century, governments in high-income countries such as Canada have invested heavily in health care, also known as sicknesses care, of their citizens. They have also invested, albeit at a much slower pace, on a broad range of social services that affect population health indirectly through prevention of chronic diseases and public health promotion (Rose, 1992; McGinnis, 2002). A recent strand of the health literature has statistically isolated the relative health benefits of these two competing forms of government expenditures. Several Canadian researchers in this literature have shown that, in standard constant-parameter health indicator models, the ratio of social services to health care spending is systematically associated with higher life expectancy and lower mortality (Dalton et al., 2018). Many international researchers have documented the same evidence for the OECD countries using cross-country panel data (Bradley et al., 2011; Bradley et al., 2013; Bradley et al., 2016). Accordingly, researchers in this strand of the health literature recommend that, for a healthier population, the Canadian government and of other OECD countries, should switch expenditure from health care to the provision of social services. If valid, this policy strategy would provide high-income countries a seemingly costless way to improve population health.

The primary purpose of this paper is to evaluate the robustness of the central findings and the policy recommendation of the literature cited above using a national time series dataset from Canada. We implement our robustness investigation in two steps. In step 1, we extend the health-indicator models typically estimated in this literature in three important directions, to see whether the key findings of the literature hold up against these changes. The first of these changes consists of augmenting the constant-parameter health models estimated in the exiting literature to time-varying parameters models. Allowing time variation in the parameters of health models is a natural consequence of diminishing marginal returns to health care spending, assuming that rapid growth in 
health care spending during the past decades have exhausted most of the easy medical interventions to extend life and reduce deaths. Furthermore, if diminishing returns have driven down the marginal health benefits of healthcare spending below those of social services spending, then this would provide a plausible explanation for the key finding of the existing literature. It may be worth noting here that our reasoning about diminishing marginal returns to healthcare spending is quite distinct from the concern expressed by some researchers about the sustainability of health care spending in an era of ageing population and tight government budgets (Skinner et al., 2011; Liaropolos \& Goranitis, 2015).

Our second extension of the existing health models consists of the introduction of dynamics or the delayed effects of many determinants of population health. For example, the health effects of expenditure on social services, alcohol, and tobacco are likely to be cumulative, rather than instantaneous. In fully specified dynamic models, the lagged effects of these variables may be both long and continuous (Shaw, Horrace, \& Vogel, 2005). However, given the degrees of freedom problem imposed by our sample size 1980-2014, we introduce a discontinuous 5-year lag for several of the determinants of population health.

In our third and final extension, we disaggregate health care spending into three components: hospital care, health professionals (physicians plus other health professionals) and drugs. These three components together account for nearly 70 percent of the annual public sector healthcare spending in Canada. The Canadian Institute of health Information (CIHI) table C.3.3 gives the break down of the per-capita annual public- sector health expenditure by use of funds into nine different categories. However, we only focus on the three components mentioned above because the health benefits of these components compared to their costs are highly controversial in the literature. For example, some researchers have argued that many new drugs introduced in Canada each year do not represent true clinical innovations or progress in medical technology; rather they are simply "me toos" whose health benefits are minimal compared to their high costs (Lee, 2007; Morgan et al., 2005). Others have argued that hospital cost and physicians salaries are the two major drivers of the rapid long-term growth in healthcare costs - a phenomenon sometimes referred to as the 'cost disease' (Barer, et al., 2003; Baumol, 1993). The decomposition we consider in this paper enable us to study the separate health effects of each component of health care spending vis-a-vis the health effects of expenditure on social services. The focus of the existing literature on the health effects of aggregate health care spending masks the separate performances of the individual components.

Given the extensions described in step 1, in step 2 we estimate both static and dynamic variants of the traditional constant-parameter, as well as, the augmented time-varying parameter health models. As in the existing literature we estimate the constant parameter models with ordinary least squares (OLS), and the time-varying parameter models with the flexible least squares (FLS) estimator (Kabala \& Tesfatsion, 1996). We then conduct a comparative analysis of the empirical performances of the augmented models to the benchmark constant-parameter models estimated in the existing literature.

It is important to note here that time variation in the coefficients of health models may arise from two separate sources: diminishing marginal benefits to health care spending and changes in health policy. The former is likely to result in gradual changes in the coefficients of health models, and the latter may cause sudden shifts of structural breaks in the coefficients. The FLS estimator can account for both of the types of changes. In fact, the FLS estimator produces estimates of the entire time path of each coefficient. It does so by minimizing the sum of the squared errors resulting from two potential sources of specification errors in health models: observational errors, as in the case of the OLS estimator, and dynamic errors due to time variation in the model coefficients (see section 4 for details).

Finally, we note that, in this paper, we offer new evidence by conducting a longitudinal study of four separate population health indicators taken from Canada's national health data over the period 1980-2014. These health indicators are the average life expectancy at birth, the average life expectancy at age 65 , premature and preventable deaths, and infant mortality. We expect that while major changes in health policy may cause structural breaks in these health indicators, diminishing marginal returns to health care spending is likely to induce gradual time variation in the parameters of the health-indicator models. We, therefore, subject each health indicator to formal econometric tests of a single break (Hansen, 1997), as well as, of multiple-breaks (Bai \& Perron, 2003) of unknown timing. For evidence of time variation in indicator-model parameters, we apply the residual-based tests of model instability (Hansen, 1992) and the RESET test of general model misspecification (Ramsey, 1969) to the constant-parameter health models estimated in the traditional health literature. We also estimate each of the health indicator models by using the FLS procedure, in order to see the extent of time variation in the parameters. 
Section 2 describes the four health indicators (dependent variables) and their potential determinants (explanatory variables), and provides some preliminary evidence of diminishing marginal returns to health care spending. Section 3 presents the algebraic specifications of the constant-parameter and the time-varying parameter health models and compares their OLS and FLS estimators. Section 4 presents the estimation results. Section 5 concludes the paper with a description of its main findings and limitations.

\section{Population health Models: Background Literature}

\subsection{Health Indicators: Dependent Variables of Health Models}

Following a consensus among health researchers, we denote population health by a set of four health indicator variables that measure the health status of the population, as well as, indicate the performance of the health system of a country. The first and the most common among these indicators is the average life expectancy at birth, which measures the number of years a new-born baby can expect to live on average, given the prevailing mortality rates. In Canada, a newborn female has a somewhat higher average life expectancy than a newborn male, for reasons related to either genetics or the relative riskiness of the type of work male and female workers do (CIHI, 2012). In the present study, we examine the common determinants of the average life expectancy at birth of both male and female, which we denote by the notation, $\mathrm{LE}_{0}$. As may be expected, the average life expectancy also varies with age; typically, the remaining number of years an individual (male or female) may expect to live declines at higher age. We, therefore, also study the determinants of life expectancy at age 65, which we denote by the notation, $\mathrm{LE}_{65}$.

The two remaining health indicators are measures of rates of mortality. One of these is the rate of premature death per 100,000 population, which measures the death rate of individuals younger than age 75 . Premature death hits Canadians hard every year. For example, in 2008, there were 67,127 potentially avoidable deaths from treatable and preventable causes, which represents 72 percent of premature deaths in that year. In this paper, we study the determinants of premature deaths, which we denote by the notation PD. The fourth and final indicator of health we study is infant mortality per 1000 , which we denote by the notation, IM. These four population health indicators represent the dependent variables in our health models.

\subsection{Determinants of Population Health: Explanatory Variables}

Health specialists have long recognized that population health is determined by the interaction of a wide variety of variables besides spending on health care (Evans \& Stoddart, 1990; Cremieux et al., 1999). These potential determinants of health include the socio-economic, demographic, life style, environmental and genetic determinants of health. As outlined in the introduction of the paper, a recent stand of the health literature emphasizes above others, the social determinants of health. In this view, public expenditure on social services compete with health care spending, since they also extend life and prevent death by reducing the health risks of the population to many chronic diseases, including cardiovascular conditions, cancers, mental disorders, respiratory conditions and diabetes (McDaid et al., 2015). A key finding of this body of research, which is the focus of the present study, is that public sector spending on social services has a bigger marginal effect on life expectancy and mortality rates than spending on health care services. Consequently, advocates of this research recommend that, for better population health, governments in Canada and other high income countries should switch spending from health care to social services (Dutton et al., 2018; Bradley et al., 2016).

Given the uncertainty noted above, we first select a set of ten potential determinants of population health and then rely on the general-to-specific modeling strategy (Hendry \& Krolzig, 2003) to determine the subset of variables that best explains each of the four health indicator variables. Following this strategy, we include in our initial set of potential explanatory variables, two public-sector determinants of health, namely, government real health care expenditure per capita (HCE) and government real per-capita spending on social services (SS). We expect, a priori, each of these variables to be positively associated with average life expectancy and negatively associated with mortality rates. However, given the controversy in the literature surrounding their relative health benefits, we formally test two separate hypotheses about these competing public sector determinants of health.

The primary hypothesis we investigate concerns the traditional claim that the health benefits of SS are quantitatively bigger than the health benefits of HCE. We also evaluate the validity of the related hypothesis that the heath benefits of SS are quantitatively bigger that health benefits of each of the major components of HCE, including real per-capita expenditures on hospital care (HOSP), real per-capita expenditures on health professionals (PHYS), and real per-capita expenditures on drugs (DRUGS).

Under Canada's single-payer health insurance system, about 70 percent of the annual per-capita spending on health care is tax-financed and the remaining 30 percent comes from private, out-of-pocket funds. We, therefore, 
include several private sector determinants of health as potential control variables in our models. We include three such variables from the socio-economic determinants of health: the real per-capita gross national income (GNI), Gini coefficient (GINI), and the national unemployment rate (UN), A priori, we expect GNI to be positively associated with life expectancy and negatively associated with mortality rates (Wilkinson \& Pickett, 2011). Because GINI and UN denote proxies for income inequality, we expect these variables to be negatively associated with life expectancy and positively associated with mortality rates. However, some authors have argued that recessions (periods of high unemployment) are good for health, because the unemployed are free from the stress of work and have more time to exercise (Ruhm, 2000).

From the demographic determinants of health, we include two variables in our initial set of explanatory variables: proportion of women in the population (SEX) and the proportion of the population 65 years old (POP65). We expect SEX and POP65 to have a positive and negative association to life expectancy respectively, because women have a higher life expectancy compared to men and because the remaining number of years of life is typically lower at higher age (Cremieux et al., 1999). We also include two proxy variables from the life-style determinants of health: real per-capital expenditures on tobacco (TOBC) and alcohol (ALCO). We expect these variables to have a negative association with life expectancy and a positive association with mortality rates. Finally, from the environmental determinants of health we include the urbanization rate (URBAN) - the percentage of the population living in urban areas. Urbanization can have either a positive or a negative effect on health, depending on the nature of urbanization (WHO, 1991).

Table 1 below describes the definition of each variable in our initial dataset, the notation we use to denote the variable and the data source from which we obtain time series data for each variable.

Table 1. Definition of variables, notations and data sources

\begin{tabular}{lcc}
\hline Definition of variable & Notation & Data Source \\
\hline Average life expectancy at birth & LE $_{0}$ & SC table 13-10-0114-01 \\
Average life expectancy at age 65 & LE $_{65}$ & SC table 13-10-0114-01 \\
Premature mortality rate per 100,000 & PD & SC table 13-10-0114-01 \\
Infant mortality rate per 1000 & IM & SC table 13-10-0114-01 \\
Pub. sector real per-capita healthcare spending & HCE & CIHI table D.1.1.3 - D.1.10.3 \\
Pub. sector real per-capita social services spending & SS & (Kneebone \& Wilkins, 2016) \\
Pub. sector real per-capita spending on hospital care & HOSP & CIHI table D.1.1.3 - D.1.10.3 \\
Pub. sector real per-capita spending on health professionals & PHYS & CIHI table D.1.1.3 - D.1.10.3 \\
Pub. sector real per-capita spending on drugs & DRUGS & CIHI table D.1.1.3 - D.1.10.3 \\
Real per-capita spending on tobacco & TOBC & SC table 36-10-0225-01 \\
Real per-capita spending on Alcohol & ALCO & SC table 36-10-0225-01 \\
Real per-capital gross national income & GNI & SC table 36-10-0229-01 \\
Measure of income inequality & GINI & (constructed by author) \\
National unemployment rate & UN & SC table14-10-0023-01 \\
Proportion of female in the population & SEX & SC table17-10-0005-01 \\
Proportion of people aged 65 in the population & POP & SC table 17-10-0005-01 \\
Proportion of people who live in urban areas & URBAN & SC table 36-10-0229-01 \\
\hline
\end{tabular}

Note. CIHI stands for Canadian Institute for Health Information; SC Stands for Statistics Canada.

\subsection{Preliminary Evidence of Diminishing Marginal Returns}

A preliminary graphical examination of the health indicators provides valuable insights for the empirical modelling of the health data at hand. Below we present four time plots Fig 1- Fig 4; each plot compares a health indicator (measured on the vertical right scale) against the three components of heath expenditures (measured on the left vertical scale). Even a cursory look at the charts shows what has happened, over the long haul, to population life expectancy at birth (Fig1) and at age 65 (Fig 2), and also to mortality rates, premature and preventable deaths (Fig 3) and infant mortality (Fig 4). Each of the health indicators has a long-term trend; the two life expectancies have a rising trend over time, while the two mortality rates have fallen with time.

A closer look at the figures reveals that life expectancies have trended up over the entire period at a much slower pace than the rising trends of each of the three components of health expenditures (hospital care, drugs and physicians), suggesting a general pattern of diminishing marginal returns to health care expenditures. The same pattern is also evident in the two mortality rates; both preventable deaths and infant mortality rates have declined 
at a slower pace than the pace of increase in the three components of health expenditures, again suggesting a systematic pattern of diminishing returns to health care expenditures.

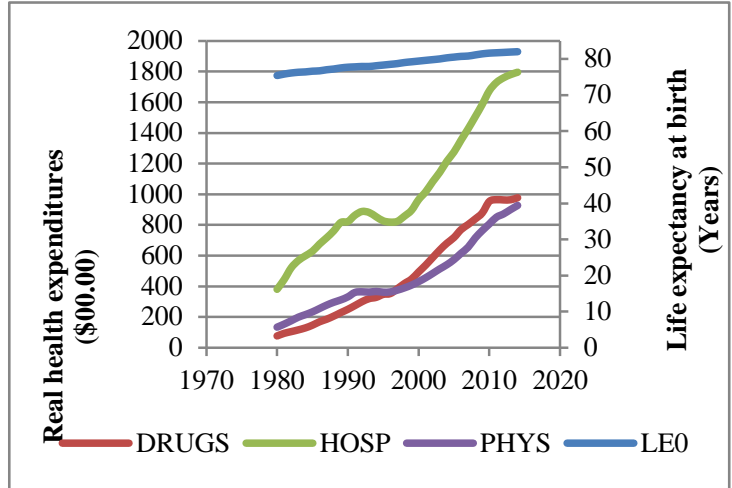

Figure 1. Real per-capita health expenditures (left scale) vs. life expectancy at birth (right scale)

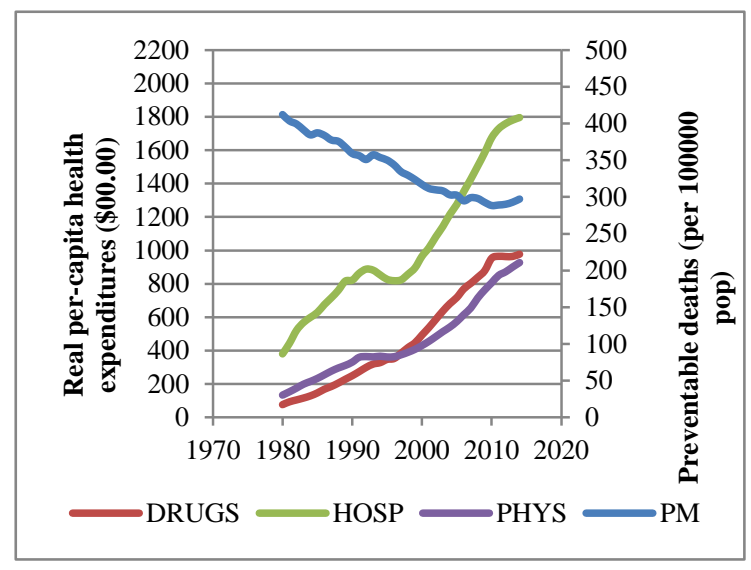

Figure 3. Real per-capita health expenditures (left scale) vs. preventable deaths (right scale)

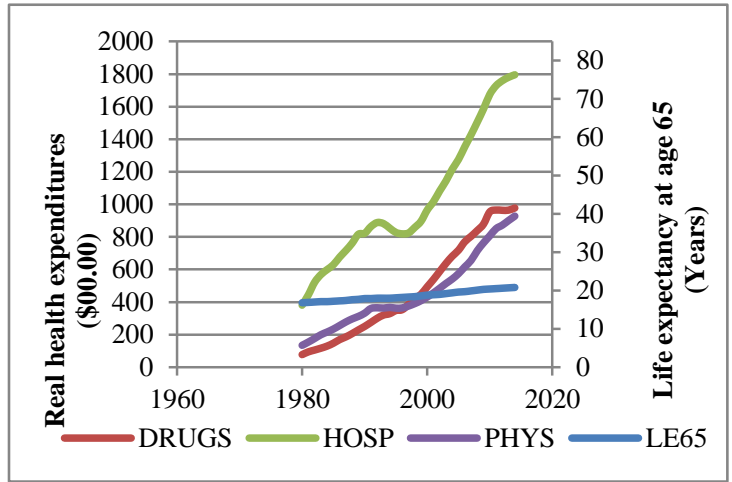

Figure 2. Real per-capita health expenditures (left scale) vs. life expectancy at age 65 (right scale)

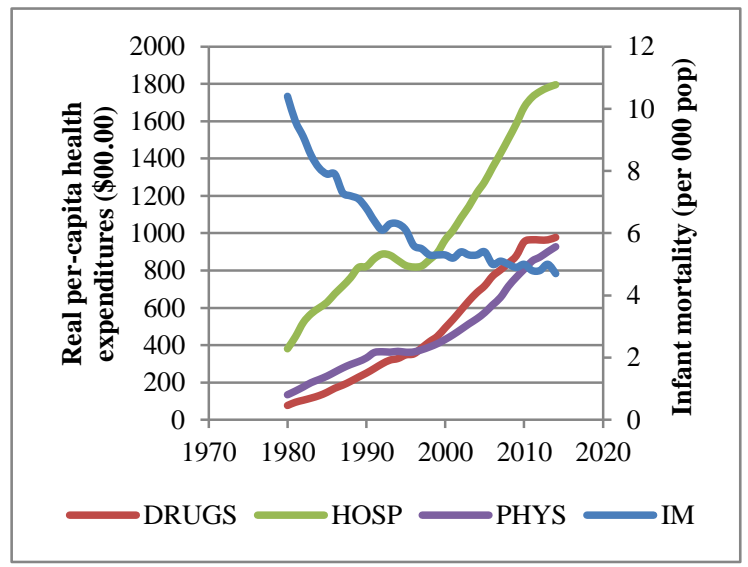

Figure 4. Real per-capital health expenditures (left scale) vs. Infant mortality (right scale)

Given the preliminary graphical evidence, we seek formal evidence of diminishing marginal returns to health care spending and of the nature of the long-term trend observed in each of the health indicators. In table 2 below, we present results of econometric tests of structural breaks and the test results of whether the trend is deterministic (perfectly predictable) or stochastic (unpredictable) for each of the health indicators. As we have already stated in the introduction, structural breaks in health indicators can be caused by major changes in health policy or be the result of diminishing marginal returns to health care spending. If the trend component of a health indicator is deterministic, then we can simply add a time trend to denote the trend component in health-indicator model. Authors in the existing health literature typically assume the trend component is deterministic and adds a time trend to each health indicator model. However, if the trend is stochastic, then an alternative approach called the vector error-correction model is a more effective way to model the trend component (Engle \& Granger, 1987).

The evidence presented in table 2 shows that both the Quandt-Andrew test of a single break and the Bai-Perron test of multiple breaks of unknown timing confirm that each of the four health indicators contains at least one structural break. The null hypothesis for the KPSS test is that the health indicator variable under investigation is stationary around a time trend and the alternative hypothesis is that the variable contains a stochastic trend (a unit root). The test results show that we cannot reject the null hypothesis for three of the four health indicators, suggesting that the best way to represent the trend component is by a time trend. Thus, following the existing literature, the health models we estimate in this paper denote the trend component by a time trend variable (see section 3 below). 
Table 2. Structural breaks and long-term trends in popular population health indicators

\begin{tabular}{|c|c|c|c|c|c|c|c|}
\hline \multirow{4}{*}{$\begin{array}{l}\text { Health Indicator } \\
\text { LE at birth }\end{array}$} & \multicolumn{4}{|c|}{ Tests of Structural Breaks } & \multicolumn{3}{|c|}{ Presence of Long term Trend } \\
\hline & \multirow{2}{*}{\multicolumn{2}{|c|}{$\begin{array}{l}\text { Quandt-Andrews Single } \\
\text { break (P values) }\end{array}$}} & \multirow{2}{*}{\multicolumn{2}{|c|}{ Bai-Perron Multiple breaks }} & \multicolumn{2}{|c|}{ KPSS Test } & \multirow{3}{*}{$\begin{array}{c}\text { Graphical Evidence } \\
\text { Yes }\end{array}$} \\
\hline & & & & & \multirow{3}{*}{$\begin{array}{l}\text { Level } \\
0.078^{*} \\
(0.146)\end{array}$} & \multirow{3}{*}{$\begin{array}{r}\text { Diff } \\
0.082 * \\
(0.146)\end{array}$} & \\
\hline & F-test & 0.000 & 0 vs. 1 & $131.02 *$ & & & \\
\hline & Wald & 0.000 & & (1995) & & & \\
\hline & Wald & 0.000 & 1 vs. 2 & $\begin{array}{l}5.65^{*} \\
(1989)\end{array}$ & & & \\
\hline & & & 2 vs. 3 & $\begin{array}{l}6.47^{*} \\
(2000)\end{array}$ & & & \\
\hline & & & 3 vs. 4 & 4.07 & & & \\
\hline \multirow[t]{2}{*}{ LE at age 65} & F-test & 0.000 & 0 vs. 1 & $\begin{array}{c}109.16^{*} \\
(1995)\end{array}$ & $\begin{array}{c}0.173 \\
(0.146)\end{array}$ & $\begin{array}{l}0.084 * \\
(0.146)\end{array}$ & Yes \\
\hline & Wald & 0.000 & 1 vs. 2 & 4.21 & & & \\
\hline Preventable & F-test & 0.000 & 0 vs. 1 & $\begin{array}{c}117.31 * \\
(1995)\end{array}$ & $\begin{array}{c}0.136 \\
(0.146)\end{array}$ & $\begin{array}{c}0137 \\
(0.146)\end{array}$ & Yes \\
\hline Deaths & Wald & 0.000 & 1 vs. 2 & 3.64 & & & \\
\hline Infant & F-test & 0.000 & 0 vs. 1 & $\begin{array}{l}63.06^{*} \\
(1996)\end{array}$ & $\begin{array}{c}0.212 \\
(0.146)\end{array}$ & $\begin{array}{l}0.092) \\
(0.146)\end{array}$ & Yes \\
\hline \multirow[t]{2}{*}{ mortality } & Wald & 0.000 & 1 vs. 2 & $\begin{array}{l}6.17^{*} \\
(1985)\end{array}$ & & & \\
\hline & & & 2 vs. 3 & 2.15 & & & \\
\hline
\end{tabular}

Note 1. The null hypothesis for the Quandt-Andrews test is that there is no breakpoint within $15 \%$ trimmed data.

Note 2 . The * for the Bai-Perron test of $\mathrm{L}+1$ vs. L sequentially determined break indicates statistical significance at the $5 \%$ level. We report the estimated break date in parenthesis underneath each statistically significant break.

Note 3. We report the KPSS test statistic and its critical value for the 5\% significance level in parenthesis below the test statistic.

\section{Constant vs. Time-Varying Parameter Health Models: Specification}

Given the time series properties of the population health indicators (see section 2.1) and the potential explanatory variables described above, it is possible to adopt two different approaches to modelling population health: a fixed-coefficient modelling approach as is typically employed in the exiting health literature or a time-varying modelling approach employed in this paper. To fully appreciate the differences and also the similarities between these two approaches, we represent below the algebraic specification of each modelling approach, using the life expectancy at birth $\left(L E_{0}\right)$ as our illustrative health indicator:

Fixed-parameter health-indicator model:

$$
\begin{gathered}
\ln \left(L E_{0}\right) t=\beta_{0}+\beta_{1} \ln (H C E)_{t}+\beta_{2} \ln (S S)_{t}+\beta_{3} \ln (G N I)_{t}+\beta_{4} \ln (U N)_{t}+\beta_{5} \ln (G I N I)_{t}+\beta_{6} \ln (A G E 65)_{t}+ \\
\beta_{7} \ln (U R B A N)_{t}+\beta_{8} \ln (A L C O)_{t}+\beta_{9} \ln (T O B C)_{t}+\beta_{10 t}(T R E N D)+\varepsilon_{t} \quad \mathrm{t}=1,2, \ldots \ldots, \mathrm{T}
\end{gathered}
$$

Time-varying parameter health-indicator model:

$$
\begin{aligned}
& \ln \left(L E_{0}\right) t=\beta_{0 t}+\beta_{1 t} \ln (H O S P)_{t}+\beta_{2 t} \ln (P H Y S)_{t}+\beta_{3 t} \ln (D R U G S)_{t}+\beta_{4 t} \ln (S S)_{t}+\beta_{5 t} \ln (G N I)_{t}+ \\
& \beta_{6 t} \ln (U N)_{t}+\beta_{7 t} \ln (G I N I)_{t}+\beta_{8 t} \ln (A G E 65)_{t}+\beta_{9 t} \ln (U R B A N)_{t}+\beta_{10 t} \ln (A L C O)_{t}+ \\
& \beta_{11 t} \ln (\text { TOBC })_{t}+\beta_{11 t}(\text { TREND })+\varepsilon_{t} \quad \mathrm{t}=1,2, \ldots ., \mathrm{T} \\
& \text { where, } \quad \beta_{i t=} \beta_{i, t-1}+v_{i t} \quad \mathrm{i}=1,2, \ldots ., \mathrm{k}
\end{aligned}
$$

There are two notable similarities and two major differences between the health model 1 and model 2 . The first similarity is that the explanatory variables in the two models are essentially the same; the only difference is that model 1 analyzes the health effects of aggregate expenditure on health care (HCE) and model 2 investigates the health effects of the components of healthcare expenditure - hospital care (HOSP), health professionals (PHYS), drugs (DRUGS). All of the other control variables in the two models are the same. The second similarity is the double-logarithmic functional form of both models; this means that the coefficients in both models denote elasticity of life expectancy at birth (LE0) with respect to each of the explanatory variables.

Of the two differences between the models, the first difference is that model 2 accounts for two potential sources of specification errors in health production: measurement errors $\left(\epsilon_{t}\right)$, associated with the choice of (wrong set of) explanatory variables and dynamic errors $\left(\mathrm{v}_{\mathrm{t}}\right)$ associated with possible time-variation in the coefficients of the model. By contrast, model 1 sets the dynamic errors to zero (by assumption); it only accounts for measurement errors in the specification of the health model. This means that model 1 can be estimated with the traditional 
OLS estimator, but model 2 must be estimated by using a flexible least squares (FLS) estimator (Kabala and Tesfatsion, 1996) that can account for both the measurement and the dynamic errors in the specification of the model.

In fact, the FLS estimates of the time-varying coefficients for model 2 are obtained by minimizing a weighted sum of squares of the measurement errors and the dynamic errors: $\sum_{\mathrm{t}=1}^{\mathrm{T}} \delta \hat{v}_{\mathrm{t}}^{2} \hat{\mathrm{v}}_{\mathrm{t}}^{2}+\sum_{\mathrm{t}=1}^{\mathrm{T}} \hat{\varepsilon}_{\mathrm{t}}^{2} \hat{\varepsilon}_{\mathrm{t}}^{2}$. The parameter $\delta$ in the optimization problem is a scaler; the researcher sets the value of $\delta$ to control the weighting scheme for trading off measurement and dynamic errors. At one extreme, when $\delta$ is set at $\delta=0$, the investigator is assuming that dynamic errors (parameter instability) are not at all costly; in this case the FLS estimates of model 2 can easily diverge from the constant-coefficient OLS estimates of model 1 . As $\delta$ is set to higher values, the investigator is saying that it is now increasingly more costly to permit dynamic errors and when $\delta$ is set at $\delta=1$ the FLS estimates are forced to converge to the constant-coefficient OLS estimates.

The second difference between model 1 and model 2 is that the time-varying coefficient model 2 permits a flexible pattern of diminishing marginal health returns to each input; by contrast, model 1 allows a restricted pattern of diminishing marginal health effects to each explanatory variable. To see this more clearly, consider, for example, the elasticity of life expectancy at birth, $\mathrm{LE}_{0}$ with respect to the aggregate expenditure on health care, HCE. This elasticity is given by, $\varepsilon_{L E 0, H}=\frac{\delta\left(L E_{0}\right)}{\delta(H C E)} \times \frac{H C E}{L E_{0}}$, where $\frac{\delta\left(L E_{0}\right)}{\delta(H C E)}$ denotes the marginal effect of healthcare expenditure (HCE) on life expectancy ( $\left.\mathrm{LE}_{0}\right)$. It is now not difficult to see that, if $\varepsilon_{L E 0, H}$ is to remain constant then as $\frac{H C E}{L E_{0}}$ rises over time, $\frac{\delta\left(L E_{0}\right)}{\delta(H E A L T H)}$ must fall proportionately over time. However, elasticity may not remain constant, especially in long time series data; and then the estimation of model 1 , rather than model 2 , may involve significant loss of information.

In summary, we note that if the coefficients of the population health-indicator models change through time, as the evidence presented in Table 1 suggests, then the estimation of model 1 using the fixed-coefficient OLS estimator, rather than model 2 using the FLS estimator, may result in significant loss of information. In addition, it may also result in errors of inferences. In section 4 below, we report the FLS and the OLS estimation results of model 2 and model 1 respectively, for each of the four population health-indicators under investigation: life expectancy at birth (LE0), life expectancy at age 65 (LE65), premature and preventable deaths (PD), and infant mortality (IM).

\section{Estimation Results for Health Model 1 and Model 2}

\subsection{Results for the Static Versions of Model 1 and Model 2}

In practice, the FLS procedure generates entire time paths of the estimates of model 2 coefficients over the entire period 1980-2014. To get an early sense of the extent of time variation, we display the time path of the coefficient attached to health care spending from the static version of each of the four health indicator models in Fig 5 through Fig 8 below.

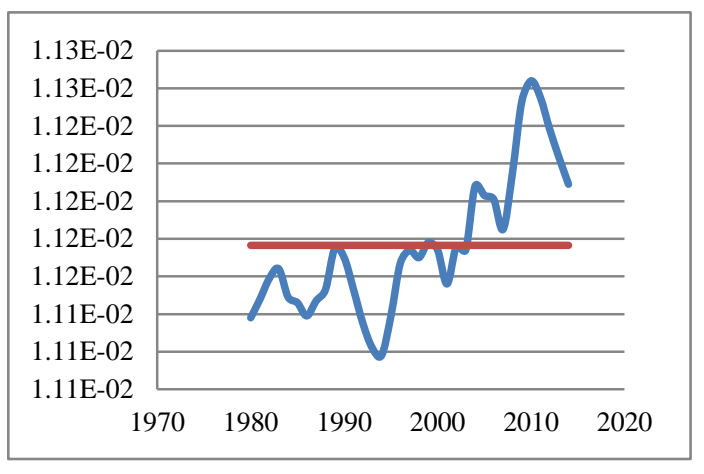

Figure 5. Time variation in the coefficient of health care spending in LE0 equation

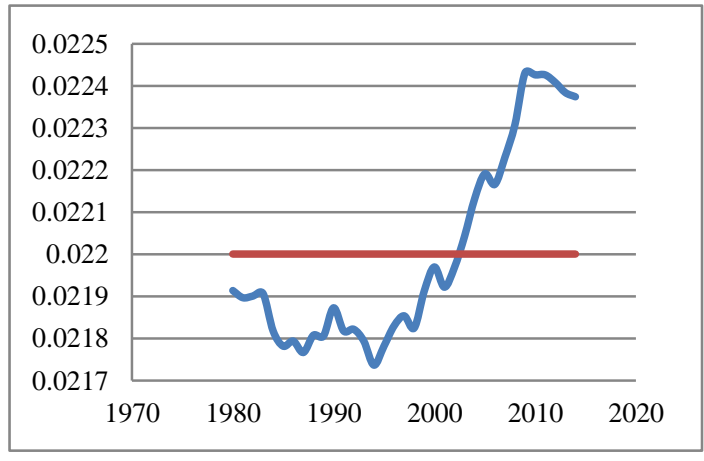

Figure 6. Time variation in the coefficient of health care spending in LE65 equation 


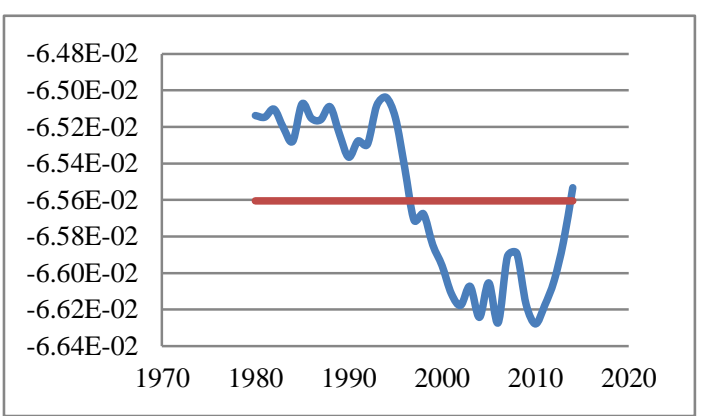

Figure 7. Time variation in the coefficient of health care spending in the PD equation

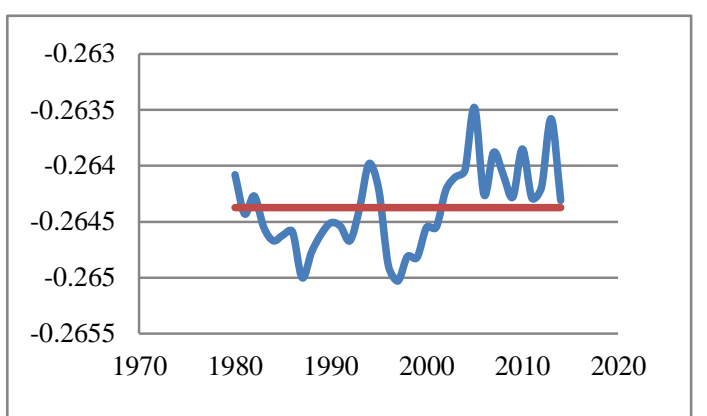

Figure 8. Time variation in the coefficient of health care spending in the IM equation

The graphical evidence presented in Fig 5 - Fig 8 clearly signal that time variation in the parameters is likely to be an important feature of health indicator models.

In Table 3 below, we report the summary statistics for the FLS estimation results, including the mean coefficient estimates and the associated standard deviations shown in parenthesis below each estimate. We also report, for each health indicator, the costs associated with the measurement errors (SS M-Errors) and the dynamic errors (SS D-Errors). In addition, for purposes of comparison, in table 3 we also summarize the OLS estimates for the fixed-coefficient model 1 for each of the four health indicators. The cost estimates reported at the bottom of table 3 for the OLS estimator were generated by FLS for $\delta=0.99999$.

Table 3. The FLS and OLS estimation results for each health indicator: 1980-2014

\begin{tabular}{|c|c|c|c|c|c|c|c|c|c|c|}
\hline & \multicolumn{2}{|c|}{$\mathrm{LE}_{0}$} & \multicolumn{2}{|c|}{$\mathrm{LE}_{0}$} & \multicolumn{2}{|c|}{$\mathrm{LE}_{65}$} & \multicolumn{2}{|c|}{$\mathrm{PD}$} & \multicolumn{2}{|c|}{$\mathrm{IM}$} \\
\hline & $\begin{array}{c}\text { OLS } \\
(1)\end{array}$ & $\begin{array}{c}\text { FLS } \\
(2)\end{array}$ & $\begin{array}{c}\text { OLS } \\
(3)\end{array}$ & $\begin{array}{c}\text { FLS } \\
(4)\end{array}$ & $\begin{array}{l}\text { OLS } \\
(5)\end{array}$ & $\begin{array}{c}\text { FLS } \\
(6)\end{array}$ & $\begin{array}{c}\text { OLS } \\
(7)\end{array}$ & $\begin{array}{c}\text { FLS } \\
(8)\end{array}$ & $\begin{array}{l}\text { OLS } \\
(9)\end{array}$ & $\begin{array}{l}\text { FLS } \\
(10)\end{array}$ \\
\hline $\mathrm{HCE}$ & $\begin{array}{l}0.006 \\
(\mathbf{0 . 0 0})\end{array}$ & $\begin{array}{l}0.004 \\
(\mathbf{0 . 0 0})\end{array}$ & & & & & & & & \\
\hline HOSP & & & $\begin{array}{l}0.022 \\
(\mathbf{0 . 0 4})\end{array}$ & $\begin{array}{l}0.026 \\
(\mathbf{0 . 0 0})\end{array}$ & $\begin{array}{l}0.109 \\
(\mathbf{0 . 0 0})\end{array}$ & $\begin{array}{l}0.967 \\
(\mathbf{0 . 0 0})\end{array}$ & $\begin{array}{r}-0.152 \\
(\mathbf{0 . 0 3})\end{array}$ & $\begin{array}{c}-0.078 \\
(\mathbf{0 . 0 1})\end{array}$ & $\begin{array}{l}0.069 \\
(0.79)\end{array}$ & $\begin{array}{l}0.345 \\
(\mathbf{0 . 0 0})\end{array}$ \\
\hline PHYS & & & $\begin{array}{l}0.001 \\
(0.98)\end{array}$ & $\begin{array}{r}-0.010 \\
(\mathbf{0 . 0 0})\end{array}$ & $\begin{array}{l}-0.019 \\
(0.34)\end{array}$ & $\begin{array}{l}-0.015 \\
(\mathbf{0 . 0 0})\end{array}$ & $\begin{array}{c}-0.104 \\
(0.11)\end{array}$ & $\begin{array}{l}-0.044 \\
(\mathbf{0 . 0 1})\end{array}$ & $\begin{array}{l}-0.222 \\
(0.17)\end{array}$ & $\begin{array}{r}-0.328 \\
(\mathbf{0 . 0 0})\end{array}$ \\
\hline DRUGS & & & $\begin{array}{l}0.002 \\
(0.66)\end{array}$ & $\begin{array}{l}0.006 \\
(\mathbf{0 . 0 0})\end{array}$ & $\begin{array}{l}0.018 \\
(\mathbf{0 . 0 5})\end{array}$ & $\begin{array}{l}0.018 \\
(\mathbf{0 . 0 0})\end{array}$ & $\begin{array}{r}-0.135 \\
(\mathbf{0 . 0 0})\end{array}$ & $\begin{array}{r}-0.148 \\
(\mathbf{0 . 0 1})\end{array}$ & $\begin{array}{r}-0.227 \\
(\mathbf{0 . 0 3})\end{array}$ & $\begin{array}{l}-0.259 \\
(\mathbf{0 . 0 0})\end{array}$ \\
\hline SS & $\begin{array}{c}0.007 \\
(0.304)\end{array}$ & $\begin{array}{l}0.006 \\
(\mathbf{0 . 0 0})\end{array}$ & $\begin{array}{l}0.008 \\
(0.17)\end{array}$ & $\begin{array}{l}0.016 \\
(\mathbf{0 . 0 0})\end{array}$ & $\begin{array}{l}0.014 \\
(0.36)\end{array}$ & $\begin{array}{l}0.003 \\
(\mathbf{0 . 0 0})\end{array}$ & $\begin{array}{r}-0.051 \\
(\mathbf{0 . 0 3})\end{array}$ & $\begin{array}{l}-0.084 \\
(\mathbf{0 . 0 0})\end{array}$ & $\begin{array}{r}-0.052 \\
(0.71)\end{array}$ & $\begin{array}{r}-0.345 \\
(\mathbf{0 . 0 1})\end{array}$ \\
\hline AGE65 & $\begin{array}{l}0.047 \\
(\mathbf{0 . 0 1})\end{array}$ & $\begin{array}{c}0.67 \\
(\mathbf{0 . 0 0})\end{array}$ & $\begin{array}{l}0.046 \\
(\mathbf{0 . 0 2})\end{array}$ & $\begin{array}{l}0.058 \\
(\mathbf{0 . 0 0})\end{array}$ & $\begin{array}{l}-0.182 \\
(0.15)\end{array}$ & $\begin{array}{l}0.189 \\
(\mathbf{0 . 0 0})\end{array}$ & $\begin{array}{l}0.411 \\
(\mathbf{0 . 0 0})\end{array}$ & $\begin{array}{l}-0.052 \\
(\mathbf{0 . 0 0})\end{array}$ & & \\
\hline ALCO & $\begin{array}{l}0.003 \\
(0.56)\end{array}$ & $\begin{array}{l}0.008 \\
(\mathbf{0 . 0 0})\end{array}$ & $\begin{array}{l}0.013 \\
(0.11)\end{array}$ & $\begin{array}{l}0.007 \\
(\mathbf{0 . 0 0})\end{array}$ & $\begin{array}{l}0.011 \\
(0.34)\end{array}$ & $\begin{array}{l}0.005 \\
(\mathbf{0 . 0 0})\end{array}$ & & & $\begin{array}{l}0.569 \\
(\mathbf{0 . 0 1})\end{array}$ & $\begin{array}{l}0.252 \\
(\mathbf{0 . 0 1})\end{array}$ \\
\hline TOBC & & & & & & & $\begin{array}{c}-0.176 \\
(\mathbf{0 . 0 1})\end{array}$ & $\begin{array}{c}-0.086 \\
(\mathbf{0 . 0 0})\end{array}$ & $\begin{array}{r}-0.412 \\
(\mathbf{0 . 0 1})\end{array}$ & $\begin{array}{r}-0.269 \\
(\mathbf{0 . 0 1 )}\end{array}$ \\
\hline URBAN & $\begin{array}{l}0.123 \\
(0.19)\end{array}$ & $\begin{array}{l}0.136 \\
(\mathbf{0 . 0 0})\end{array}$ & $\begin{array}{l}0.074 \\
(0.52)\end{array}$ & $\begin{array}{l}0.224 \\
(\mathbf{0 . 0 0})\end{array}$ & & & & & & \\
\hline GNI & & & & & $\begin{array}{l}0.027 \\
(0.35)\end{array}$ & & & & & \\
\hline TREND & $\begin{array}{l}0.001 \\
(\mathbf{0 . 0 0})\end{array}$ & $\begin{array}{l}0.014 \\
(\mathbf{0 . 0 0})\end{array}$ & $\begin{array}{l}0.002 \\
(\mathbf{0 . 0 0})\end{array}$ & $\begin{array}{l}0.012 \\
(\mathbf{0 . 0 0})\end{array}$ & $\begin{array}{l}0.003 \\
(\mathbf{0 . 0 0})\end{array}$ & $\begin{array}{l}0.053 \\
(\mathbf{0 . 0 0})\end{array}$ & $\begin{array}{r}-0.061 \\
(\mathbf{0 . 0 0})\end{array}$ & $\begin{array}{c}-.0 .057 \\
(\mathbf{0 . 0 1})\end{array}$ & $\begin{array}{r}-0.007 \\
(\mathbf{0 . 0 1})\end{array}$ & $\begin{array}{l}0.233 \\
(\mathbf{0 . 0 0})\end{array}$ \\
\hline CONST & $\begin{array}{l}2.143 \\
(\mathbf{0 . 0 0})\end{array}$ & $\begin{array}{l}1.401 \\
(\mathbf{0 . 0 0})\end{array}$ & $\begin{array}{l}2.078 \\
(\mathbf{0 . 0 0})\end{array}$ & $\begin{array}{c}1.188 \\
(\mathbf{0 . 0 0})\end{array}$ & $\begin{array}{l}0.832 \\
(\mathbf{0 . 0 0})\end{array}$ & $\begin{array}{l}0.661 \\
(\mathbf{0 . 0 0})\end{array}$ & $\begin{array}{l}3.622 \\
(\mathbf{0 . 0 0})\end{array}$ & $\begin{array}{c}-4.022 \\
(\mathbf{0 . 0 1})\end{array}$ & $\begin{array}{l}1.438 \\
(0.35)\end{array}$ & $\begin{array}{l}3.591 \\
(\mathbf{0 . 0 0})\end{array}$ \\
\hline $\begin{array}{l}\text { DW } \\
\text { Q-Stat }(8)\end{array}$ & $\begin{array}{l}1.193 \\
(\mathbf{0 . 0 1})\end{array}$ & & $\begin{array}{l}2.001 \\
(0.15)\end{array}$ & & $\begin{array}{l}1.326 \\
(\mathbf{0 . 0 4})\end{array}$ & & $\begin{array}{c}1.901 \\
(0.32)\end{array}$ & & $\begin{array}{l}1.738 \\
(0.08)\end{array}$ & \\
\hline RESET & $\begin{array}{r}-3.145 \\
(0.25)\end{array}$ & & $\begin{array}{c}-12.487 \\
(\mathbf{0 . 0 0})\end{array}$ & & $\begin{array}{r}-1.812 \\
(0.12)\end{array}$ & & $\begin{array}{r}-1.545 \\
(0.14)\end{array}$ & & $\begin{array}{l}1.387 \\
(\mathbf{0 . 0 4})\end{array}$ & \\
\hline SS M-Error & 0.540 & 0.003 & 0.485 & 0.002 & 0.375 & 0.001 & 0.001 & 0.183 & 0.004 & 1.586 \\
\hline SS D-Error & 0.000 & 0.123 & 0.000 & 0.094 & 0.000 & 0.773 & 0.000 & 7.645 & 0.000 & 63.559 \\
\hline
\end{tabular}

Note. The numbers shown in parentheses under the OLS estimates are p-values of the estimates and those under the FLS estimates are standard deviations (SDs) of the estimates; the highlighted p-values and SDs that indicate significance at $5 \%$ and in many cases $1 \%$ significance levels. The p-values and SDs that are underlined are significant at the $10 \%$ significance level. 
Several interesting results emerge from table 3. First, an overview of the goodness of fit of the traditional fixed-coefficient health modell is in order. As reported at the bottom of table 3, the Durbin-Watson (DW) statistic and also the $\mathrm{Q}(8)$ statistic indicate that model 1 estimates for three of four health indicators (LEO, LE65 and IM), model 1 suffer from a systematic pattern of residual autocorrelation. The presence of residual correlation, both at lag 1 and higher lags, suggests that model 1 is subject to some unknown specification error, arising either from omitted explanatory variable/s or from some unknown nonlinearity. The results of the Ramsey RESET test seem to confirm the presence of such specification errors, which show that a non-linear combination of the fitted values help to explain the data for two (LE65 and IM) of the three health indicators that also suffers from the residual correlation problem.

Second, on the question of the relative impacts of social services (SS) vs. health care (HCE) spending on life expectancy at birth, $\mathrm{LE}_{0}$, the OLS and the FLS estimates are in columns (2) and (3) of table 3 respectively. These results show that only the FLS estimates in column (3) are consistent with the traditional claim that public-sector spending on social services increases life expectancy at birth by more than does spending on healthcare. For example, the reported FLS elasticity estimates show that a $1 \%$ increase in healthcare spending increases $\mathrm{LE}_{0}$ by 0.006 percent, while a $1 \%$ increase in social services spending raises $\mathrm{LE}_{0}$ by only 0.004 percent. Converted to marginal abilities, these elasticity estimates imply that it requires an increase in per-capita healthcare expenditure of $\$ 62,173$ (constant 2002 dollars) compared to a per-capita increase of only $\$ 15,021$ (constant 2002 dollars) to raise life expectancy by 1 year.

Third, when we disaggregate HCE into its components, the results in columns (4) and (5) again show that the OLS estimates in column (4) do not support the existing view about the relative health benefits of social services vs. health care spending. Furthermore, the FLS estimates now reveal that the elasticity of $\mathrm{LE}_{0}$ with respect to SS spending is bigger only compared to expenditures on two of the components (PHYS and DRUGS) of health care spending, but not with respect to expenditure on hospital care (HOSP). In fact, HOSP has a bigger elasticity to raise life expectancy at birth compared to expenditure on social services. The next two columns (6) and (7) report the responses of life expectancy at age 65 ; evidently, these responses are qualitatively similar to those for the responses of life expectancy at birth in columns (4) and (5). Again, the FLS results show that the elasticity of life expectancy with respect to hospital care spending is bigger than the corresponding elasticity associated with expenditure on social services.

Fourth, turning to the estimation results for preventable deaths (cols 7 and 8 ) and infant mortality (cols 9 and 10), the pattern of responses we observed for life expectancy also seems to persist in the cases of these two mortality indicators of population health. The relative dominance of dynamic errors over measurement errors is evident. Also, as in the case for life expectancy, the traditional case for switching expenditure from HCE to SS is not supported by the OLS results; see columns (7) and (9). However, the FLS estimates in columns (8) and (10) are more in line with this traditional viewpoint. They show that SS spending have the ability to lower preventable deaths (PD) by bigger percentages compared to spending on hospital care and on medical professionals (PHYS). The FLS estimates for the responses of infant mortality are even more favourable to the traditional case for switching expenditure to social services, see column (10).

Our analysis so far has focused on the relative health effects of government spending on health care and social services; but the evidence in table 3 also extend to other (life-style) determinants of health that are individual rather than governmental responsibilities. The FLS estimates in particular show that alcohol consumption contributes markedly to reduction in the average life expectancy and to infant mortality, while the impact of tobacco consumption seems to be mainly concentrated in increasing preventable deaths and infant mortality. In addition, the age composition of the population (proportion of the population aged 65 years) appears to systematically reduce life expectancy generally and increase mortality, according to both the OLS and the FLS estimation methods.

\subsection{Results for the Dynamic Versions of Model 1 and Model 2}

We now turn to the second potential source of specification error for the poor empirical performance of the constant-parameter health model 1: dynamic or delayed effects of explanatory variables. In section 3.0 above, we found that the OLS estimation of model 1 generally resulted in systematic residual correlation problem. In this section, we augment model 1 and model 2 with lagged effects of several explanatory variables, since the health effects of some determinants of health, such as expenditure on social services, tobacco and alcohol may be cumulative, rather than instantaneous. In a fully specified dynamic health model, these lags may be both long and continuous (Shaw et al., 2005). However, due to the degrees of freedom problem imposed by the sample size, we augment several of the arguments of model 1 and model 2 with a discontinuous 5-year lag and re-estimate the 
models with the OLS and the FLS estimators respectively, for each of the four health indicators.

We report the results of this re-estimation in table 4 below. The evidence shows that the dynamic version of the health model reported in table 4 fits the data better than the static version in table 3 . For example, a comparison of the DW and the Q(8) statistics at the bottom of the two tables shows that, while table 4 estimates of model 1 are not completely free from the residual correlation problem, the extent of the problem across the four health indicators is noticeably less than that of table 3 estimates of model 1. Furthermore, the evidence also shows that the relative size of the dynamic errors vis-a-vis measurement errors in tables 4 is somewhat smaller than they are in table 3. This suggests that a proper accounting of the dynamics associated with the cumulative health effects of the determinants of health is important for minimizing specification errors in health models.

Table 4. The FLS and OLS estimation results for health indicators: Dynamic models: 1980-2014

\begin{tabular}{|c|c|c|c|c|c|c|c|c|c|c|}
\hline & \multicolumn{2}{|c|}{ LE0 } & \multicolumn{2}{|c|}{ LE0 } & \multicolumn{2}{|c|}{ LE65 } & \multicolumn{2}{|c|}{ PD } & \multicolumn{2}{|c|}{$\mathrm{IM}$} \\
\hline & $\begin{array}{c}\text { OLS } \\
(1) \\
\end{array}$ & $\begin{array}{l}\text { FLS } \\
(2) \\
\end{array}$ & $\begin{array}{c}\text { OLS } \\
(3) \\
\end{array}$ & $\begin{array}{c}\text { FLS } \\
(4) \\
\end{array}$ & $\begin{array}{c}\text { OLS } \\
(5) \\
\end{array}$ & $\begin{array}{c}\text { FLS } \\
(6) \\
\end{array}$ & $\begin{array}{c}\text { OLS } \\
(7) \\
\end{array}$ & $\begin{array}{c}\text { FLS } \\
(8) \\
\end{array}$ & $\begin{array}{c}\text { OLS } \\
(9) \\
\end{array}$ & $\begin{array}{l}\text { FLS } \\
(10) \\
\end{array}$ \\
\hline HCE & $\begin{array}{l}0.007 \\
(\mathbf{0 . 0 0})\end{array}$ & $\begin{array}{l}0.002 \\
(\mathbf{0 . 0 0})\end{array}$ & & & & & & & & \\
\hline HOSP & $\begin{array}{l}0.026 \\
(\underline{0.06})\end{array}$ & $\begin{array}{l}0.002 \\
(\mathbf{0 . 0 0})\end{array}$ & $\begin{array}{l}0.087 \\
(\mathbf{0 . 0 2})\end{array}$ & $\begin{array}{c}0.079 \\
(\mathbf{0 . 0 0})\end{array}$ & & & $\begin{array}{l}-0.211 \\
(0.25)\end{array}$ & $\begin{array}{c}-0.069 \\
(\mathbf{0 . 0 0})\end{array}$ & $\begin{array}{l}0.069 \\
(0.79)\end{array}$ & $\begin{array}{r}-0.177 \\
(\mathbf{0 . 0 0})\end{array}$ \\
\hline PHYS & $\begin{array}{l}0.017 \\
(\underline{0.08})\end{array}$ & $\begin{array}{l}0.016 \\
(\mathbf{0 . 0 0})\end{array}$ & $\begin{array}{l}0.041 \\
(\underline{0.10})\end{array}$ & $\begin{array}{r}-0.032 \\
(\mathbf{0 . 0 0})\end{array}$ & & & $\begin{array}{l}0.088 \\
(0.54)\end{array}$ & $\begin{array}{r}-0.031 \\
(\mathbf{0 . 0 1})\end{array}$ & $\begin{array}{r}-0.222 \\
(0.17)\end{array}$ & $\begin{array}{r}-0.194 \\
(\mathbf{0 . 0 0 )}\end{array}$ \\
\hline DRUGS & $\begin{array}{r}-0.006 \\
(\underline{0.07)}\end{array}$ & $\begin{array}{l}0.002 \\
(\mathbf{0 . 0 0})\end{array}$ & $\begin{array}{r}-0.015 \\
(\mathbf{0 . 0 0})\end{array}$ & $\begin{array}{c}0.024 \\
(\mathbf{0 . 0 0})\end{array}$ & $\begin{array}{l}-0.105 \\
(\mathbf{0 . 0 0})\end{array}$ & $\begin{array}{l}-0.146 \\
(\mathbf{0 . 0 0})\end{array}$ & & & $\begin{array}{r}-0.227 \\
(\mathbf{0 . 0 3})\end{array}$ & $\begin{array}{r}-0.002 \\
(\mathbf{0 . 0 0})\end{array}$ \\
\hline $\mathrm{SS}(-5)$ & $\begin{array}{l}0.008 \\
(\underline{0.10})\end{array}$ & $\begin{array}{l}0.004 \\
(\mathbf{0 . 0 0})\end{array}$ & $\begin{array}{l}0.009 \\
(\mathbf{0 . 0 3})\end{array}$ & $\begin{array}{l}0.016 \\
(\mathbf{0 . 0 0 )}\end{array}$ & $\begin{array}{l}0.019 \\
(\mathbf{0 . 0 1})\end{array}$ & $\begin{array}{l}0.032 \\
(\mathbf{0 . 0 0 )}\end{array}$ & $\begin{array}{l}-0.113 \\
(\mathbf{0 . 0 1})\end{array}$ & $\begin{array}{c}-0.066 \\
(\mathbf{0 . 0 0})\end{array}$ & $\begin{array}{r}-0.052 \\
(0.71)\end{array}$ & $\begin{array}{r}-0.083 \\
(\mathbf{0 . 0 0 )}\end{array}$ \\
\hline AGE65 & $\begin{array}{r}-0.028 \\
(0.12)\end{array}$ & $\begin{array}{l}0.044 \\
(\mathbf{0 . 0 0})\end{array}$ & $\begin{array}{l}0.049 \\
(\mathbf{0 . 0 0})\end{array}$ & $\begin{array}{c}0.005 \\
(\mathbf{0 . 0 0})\end{array}$ & $\begin{array}{l}-0.193 \\
(\mathbf{0 . 0 1})\end{array}$ & $\begin{array}{c}0.088 \\
(\mathbf{0 . 0 0})\end{array}$ & $\begin{array}{l}0.491 \\
(\mathbf{0 . 0 0})\end{array}$ & $\begin{array}{c}-0.249 \\
(\mathbf{0 . 0 0})\end{array}$ & & \\
\hline $\operatorname{ALCO}(-5)$ & $\begin{array}{l}0.004 \\
(0.19)\end{array}$ & $\begin{array}{l}0.008 \\
(\mathbf{0 . 0 0})\end{array}$ & $\begin{array}{c}-0.002 \\
(\mathbf{0 . 0 0})\end{array}$ & $\begin{array}{r}-0.012 \\
(\mathbf{0 . 0 0})\end{array}$ & $\begin{array}{l}0.006 \\
(0.69)\end{array}$ & $\begin{array}{l}0.009 \\
(\mathbf{0 . 0 0})\end{array}$ & & & $\begin{array}{l}0.569 \\
(\mathbf{0 . 0 1})\end{array}$ & $\begin{array}{l}0.065 \\
(\mathbf{0 . 0 1})\end{array}$ \\
\hline TOBC $(-5)$ & & & & & & & $\begin{array}{l}-0.012 \\
(0.84)\end{array}$ & $\begin{array}{l}-0.045 \\
(\mathbf{0 . 0 0 )}\end{array}$ & $\begin{array}{l}-0.412 \\
(\mathbf{0 . 0 1})\end{array}$ & $\begin{array}{l}-0.024 \\
(\mathbf{0 . 0 1})\end{array}$ \\
\hline URBAN(-5) & $\begin{array}{l}0.086 \\
(0.25)\end{array}$ & $\begin{array}{l}0.531 \\
(\mathbf{0 . 0 0})\end{array}$ & $\begin{array}{l}0.127 \\
(0.12)\end{array}$ & $\begin{array}{l}0.226 \\
(\mathbf{0 . 0 0})\end{array}$ & & & & & & \\
\hline GDI & & & & & $\begin{array}{l}0.068 \\
(\mathbf{0 . 0 0})\end{array}$ & & & & & \\
\hline TREND & $\begin{array}{l}0.001 \\
(\mathbf{0 . 0 0})\end{array}$ & $\begin{array}{l}0.001 \\
(\mathbf{0 . 0 0})\end{array}$ & $\begin{array}{l}0.001 \\
(\mathbf{0 . 0 0})\end{array}$ & $\begin{array}{l}0.005 \\
(\mathbf{0 . 0 0})\end{array}$ & $\begin{array}{l}0.003 \\
(\mathbf{0 . 0 0})\end{array}$ & $\begin{array}{l}0.015 \\
(\mathbf{0 . 0 0})\end{array}$ & $\begin{array}{l}-0.061 \\
(\mathbf{0 . 0 0})\end{array}$ & $\begin{array}{l}-.0 .015 \\
(\mathbf{0 . 0 1})\end{array}$ & $\begin{array}{l}-0.007 \\
(\mathbf{0 . 0 1})\end{array}$ & $\begin{array}{l}0.407 \\
(\mathbf{0 . 0 0})\end{array}$ \\
\hline CONST & $\begin{array}{l}1.642 \\
(\mathbf{0 . 0 0})\end{array}$ & $\begin{array}{l}1.117 \\
(\mathbf{0 . 0 0})\end{array}$ & $\begin{array}{l}1.631 \\
(\mathbf{0 . 0 0})\end{array}$ & $\begin{array}{l}1.117 \\
(\mathbf{0 . 0 0})\end{array}$ & $\begin{array}{l}0.963 \\
(\mathbf{0 . 0 0})\end{array}$ & $\begin{array}{l}0.294 \\
(\mathbf{0 . 0 0})\end{array}$ & $\begin{array}{l}3.127 \\
(\mathbf{0 . 0 0})\end{array}$ & $\begin{array}{l}2.884 \\
(\mathbf{0 . 0 0})\end{array}$ & $\begin{array}{l}1.122 \\
(\mathbf{0 . 0 0})\end{array}$ & $\begin{array}{l}-5.831 \\
(\mathbf{0 . 0 0})\end{array}$ \\
\hline DW & 1.219 & & 1.758 & & 2.158 & & 1.158 & & 1.738 & \\
\hline Q-Stat(8) & $(\underline{0.06})$ & & $(0.16)$ & & $(0.02)$ & & $(0.19)$ & & $(\underline{0.06})$ & \\
\hline RESET & $\begin{array}{l}-9.672 \\
(\mathbf{0 . 0 1})\end{array}$ & & $\begin{array}{l}-12.487 \\
(\mathbf{0 . 0 0})\end{array}$ & & $\begin{array}{l}-1.812 \\
(0.12)\end{array}$ & & $\begin{array}{l}-1.545 \\
(0.14)\end{array}$ & & $\begin{array}{l}1.387 \\
(\mathbf{0 . 0 4})\end{array}$ & \\
\hline SS M- Error & 0.321 & 0.002 & 0.137 & 0.011 & 1.090 & 0.161 & 3.791 & 0.115 & 1.168 & 1.153 \\
\hline SS D-Error & 0.000 & 0.081 & 0.000 & 0.094 & 0.000 & 0.534 & 0.000 & 5.791 & 0.000 & 0.001 \\
\hline
\end{tabular}

Note. The numbers shown in parentheses under the OLS estimates are p-values of the estimates and those under the FLS estimates are standard deviations (SDs) of the estimates; the heighted p-values and SDs indicate significance at $5 \%$ and in many cases $1 \%$ significance levels. The p-values and SDs that are underlined are significant at the $10 \%$ significance level.

How do the delayed effects of explanatory variables affect the relative health effects of government spending on health care and social services? In the case of aggregate healthcare spending, HCE, both the OLS and FLS estimates show that government spending on health care as well as on social services significantly increase life expectancy at birth, see columns (2) and (3). In addition, the evidence also confirms the claim that the relative size of the contribution of expenditure on social services (SS) is bigger than that of the expenditure on health care (HCE). However, the OLS and the FLS estimates do not agree with one another when we disaggregate HCE in to its components, as the results in columns (4) and (5) show. With respect to premature deaths, both the OLS 
and the FLS estimates agree that expenditure on SS a has significant ability to reduce premature deaths, but the size of the reduction is smaller than that of hospital care. The relatively bigger contribution of expenditure on hospital care also persists in the case of infant mortality reduction (see cols 9 and 10).

\section{Conclusions and Limitations of the Study}

The key take away from the results of this paper is that dynamics, both in the form of time varying parameters and also delayed effects of explanatory variables, are an important feature of population health models. The FLS estimation results presented in the paper provides confirmatory evidence of the finding for both life expectancy and mortality rates. In particular, they show that the costs associated with dynamic errors (due to time variation in parameters) are generally much bigger than the costs of measurement error in the specification of health models. A related finding is that, as claimed in the existing literature, the marginal health effects of public expenditure on social services may indeed be bigger than the marginal health effects of expenditure on health care. However, this result emerges not from the constant-parameter health models estimated in the existing literature; rather it only emerges after we account for the dynamics in the specification of the health models.

The findings of the paper are subject to several limitations. First, while we have examined the role of time varying parameters and of delayed interactions between health outcomes and the determinants of health, we have not addressed the issue of model uncertainty - the likelihood of time variation in the explanatory variables themselves. Our findings are subject to potential model uncertainty. Second, population health is likely to be a function of additional explanatory variables, including genetic predispositions of individuals to diseases and of individual life style variables, such as the intake of fruits and vegetables and of fatty foods. Lack of time series data on a consistent basis has prevented us from examining the potential impacts of such variables on health outcomes. Finally, our findings in this paper have emerged from an analysis of aggregate (national) health data for Canada; however, health policy is primarily a provincial and territorial responsibility in the country. The findings at the national level may not apply to individual provinces. We, therefore, underline the importance of conducting further studies using the provincial and territorial data.

\section{References}

Bai, J., \& Perron, P. (2003). Computation and analysis of multiple structural change models. Journal of Applied Economics, 18(1), 1-22. https://doi.org/10.1002/jae.659

Barer, M. L., Morgan, S. G., \& Evans, R. G. (2003). Strangulation or Rationalization? Costs and Access in Canadian hospitals. Longwood Review, 1(4), 1-18. https://doi.org/10.12927/hcq.2003.17241

Baumol, W. J. (1993). Healthcare, Education and the Cost Disease: A Looming Crisis for Public Choice. Public Choice, 77, 17-28. https://doi.org/10.1007/BF01049216

Bradley, E. H. et al. (2016). Variation In Health Outcomes: The Role Of Spending On Social Services, Public Health, And Health Care, 2000-09. Health Affairs, 35(5), 760-768. https://doi.org/10.1377/hlthaff.2015.0814

Bradley, E. H., \& Taylor, L. A. (2013). The American Health Care Paradox: Why Spending More Is Getting Us Less. Public Affairs.

Bradley, E. H., Elkins, B. R., Herrin, J., \& Elbel, B. (2011). Health and social services expenditures: Associations with health outcomes. BMJ Qual Saf., 20(10), 826-31. https://doi.org/10.1136/bmjqs.2010.048363

CIHI. (2012). Health Indicators. Canadian Institute of Health Information and Statistics Canada Retrieved from https://secure.cihi.ca/free_products/health_indicators_2012_en.pdf.

Cremieux et al. (1999). Health care spending as determinant of determinants of health outcomes. Health Economics, 8 6(7), 627-639. https://doi.org/10.1002/(SICI)1099-1050(199911)8:7<627::AID-HEC474>3.0.CO;2-8

Dutton, D. J., Forest, P. G., Kneebone, R. D., \& Zwicker, J. D. (2018). Effect of provincial spending on social services and health care on health outcomes in Canada: An observational longitudinal study. CMAJ, 190(3), 66-71. https://doi.org/10.1503/cmaj.170132

Engle, R. F., \& Granger, C. W. J. (1987). Co-integration and Error Correction: Representation, Estimation, and Testing. Econometrica, 55, 251-276. https://doi.org/10.2307/1913236

Evans, R. G., \& Stoddart, G. L. (1990). Producing health, consuming healthcare. Social Science and Medicine, 31(12), 1347-1363. https://doi.org/10.1016/0277-9536(90)90074-3 
Hansen, B. E. (1992). Testing for Parameter Instability in Linear Models. Journal of Policy Modeling, 14(4), 517-33. https://doi.org/10.1016/0161-8938(92)90019-9

Hansen, B. E. (1997). Approximate Asymptotic P Values for Structural-Change Tests. Journal of Business and Economic Statistics, 15(1), 60-67. https://doi.org/10.2307/1392074

Hendry, D. F., \& Krolzig, H. M. (2003). New Developments in Automatic General-to-specific Modelling, Chapter 16. In B. P. Stigum (Ed.), Econometrics and the Philosophy of Economics: Theory-Data Confrontations in Economics (pp. 379-419). Princeton University Press. https://doi.org/10.1515/9781400873234-019

Kabala, R., \& Tesfatsion, L. (1996). A multicriteria approach to model specification and estimation. Computational Statistics \& Data Analysis. Computational Statistics \& Data Analysis, 21(2), 193-214. https://doi.org/10.1016/0167-9473(94)00030-1

Kneebone, R., \& Wilkins, M. (2016). Canadian provincial government budget data, 1980/81 to 2013/2014. Canadian Public Policy, 42, 1-19. https://doi.org/10.3138/cpp.2015-046

Lee, M. (2007). How sustainable is Medicare? A closer look at aging, technology and other cost drivers in Canada's healthcare system. Canadian Centre for Policy Alternatives, 10-27. Retrieved from https://www.policyalternatives.ca/publications/reports/how-sustainable-medicare

Liaropolos, L., \& Goranitis, I. (2015). Health care financing and the sustainability of health systems. Int J Equity Health, 14, 80. https://doi.org/10.1186/s12939-015-0208-5

McGinnis, J. M., Williams-Russo, P., \& Knickman, J. R. (2002). The case for more active policy attention to health promotion. Health Aff (Millwood), 21(2), 78-93. https://doi.org/10.1377/hlthaff.21.2.78

Morgan, S. G. et al. (2005). "Breakthrough" drugs and growth in expenditure on prescription drugs in Canada. British Medical Journal, 331, 815-816. https://doi.org/10.1136/bmj.38582.703866.AE

Ramsey, J. B. (1969). Tests for Specification Errors in Classical Linear Least Squares Regression Analysis. aJournal of the Royal Statistical Society, Series B, 31, 350-371. https://doi.org/10.1111/j.2517-6161.1969.tb00796.x

Rose, G. (1992). The Strategy of Preventive Medicine. Oxford: Oxford University Press.

Ruhm, C. J. (2000). Are recessions good for your health? The Quarterly Journal of Economics, 115, 617-650. https://doi.org/10.1162/003355300554872

Shaw, J. W., Horrace, W. C., \& Vogel, R. J. (2005). The determinants of life expectancy: An analysis of the OECD health data. Southern Economics Journal, 71(4), 768-783. https://doi.org/10.2307/20062079

Skinner, B. J., \& Rovere, M. (2011). Canada's Medicare Bubble Is Government Health Spending Sustainable without User-based Funding? Studies in Health Care Policy: Fraser Institute, 1-40. Retrieved from https://www.fraserinstitute.org/sites/default/files/canadas-medicare-bubble-rev.pdf.

Tesfatsion, L., \& Veitch, J. M. (1990). U.S. money demand instability a flexible least squares approach. Journal of Economic Dynamics and Control, 14, 151-173. North-Holland. https://doi.org/10.1016/0165-1889(90)90010-E

Wilkinson, R., \& Pickett, K. (2011). The Spirit Level: Why Greater Equality Makes Societies Stronger. New York: Bloomberg Press.

World Health Organization. (1991). Health and the cities: A global overview. Technical discussion on strategies for health for all in the face of rapid urbanization. A44/Technical discussion/2. Geneva: WHO.

World Health Organization. (2015). Promoting Health, Preventing Disease: The Economic Case. Edited by McDaid D, Sassi F, Merkur S. Open University Press.

\section{Copyrights}

Copyright for this article is retained by the author(s), with first publication rights granted to the journal.

This is an open-access article distributed under the terms and conditions of the Creative Commons Attribution license (http://creativecommons.org/licenses/by/4.0/). 